\title{
Establishment of Efficient In-vitro Regeneration Protocol in 'Malbhog' Banana (Musa paradisiaca) using MWCNTs and Plant Growth Regulators
}

\author{
Indrani Chetia ${ }^{1}$, Amrita Kashyap Chaliha ${ }^{1}$, Manab Bikash Gogoi ${ }^{2 *}$ and Gaurav Verma ${ }^{3}$ \\ ${ }^{1}$ Dibrugarh University, Dibrugarh, Assam, India \\ ${ }^{2}$ Department of Agricultural Biotechnology, Assam Agriculture University, \\ Jorhat, Assam, India \\ ${ }^{3}$ Dr. S. S. Bhatnagar University Institute of Chemical Engineering \& Technology, Panjab \\ University, Chandigarh \& Co-Coordinator, Centre for Nanoscience \& Nanotechnology \\ (U.I.E.A.S.T.), Panjab University \\ *Corresponding author
}

\section{A B S T R A C T}

Keywords

Multi walled carbon nano tubes,

Functionalized

carbon nano tubes,

In-vitro

regeneration of

Malbhog banana

Article Info

Accepted:

24 July 2020

Available Online:

10 August 2020
The present study was performed to establish an efficient and standard protocol for in vitro propagation of 'Malbhog' (Musa paradisiaca, AAB genome) banana under suitable culture conditions and to study the effect of growth hormones BAP \& NAA on the growth of explants. Further, for the first time we report here the effect of MWCNTs (Multi walled carbon nano tubes) like FCNTs (Functionalized carbon nano tubes), D1 and D2 in 'Malbhog' Invitro regeneration. It was also observed that TDZ at $0.11 \mathrm{mg} / \mathrm{L}$ showed the highest response ( 7.5 shoots per explants) in terms of shoot proliferation where as root induction was found to be highest in the MS media supplemented with $1 \mathrm{mg} / \mathrm{L}$ NAA. Also, the explants grown in MS Media with FCNTs at100 $\mu \mathrm{g} / \mathrm{mL}$ ( 8.5 shoots per explants) exhibited acceleration of shoot proliferation in comparison to control without FCNTs.

\section{Introduction}

'Malbhog' (Musa paradisiaca, AAB genome), is a banana cultivar which has high commercial value in the North Eastern part of India because of its nutritional value, sweet taste and aroma. As the quality planting materials are always in demand so this requires a fast and efficient mass production of banana saplings for commercial cultivation. Tissue culture raised 'Malbhog' banana plants will reduce the problem of Panama wilt, as disease free quality propagules would be available for planting (Thangavelu et al., 2012). Micropropagated banana plants produce bunch with higher weight, more fingers and hands and more uniform fruit size and shape (Tomekpe, et al., 2011) .Various methods have been developed earlier for rapid regeneration and to overcome the shortage of planting materials (Barker, 1959; De Smet et al., 1995). Methods have 
been developed for 'Malbhog micropropagation with the effect of different plant growth regulators (Sugandh Suman and Harsh Kumar, 2015; Goswami and Handique, 2013; Roy et al., 2010). Further, in very recent times, nano particles have also been used in tissue culture for better regeneration efficiency, control of contamination and other benefits (McGehee, Diamond, et al., 2017; Helaly, Mohamed Naser et al., 2014). Silver nano particles have been employed to evaluate the effect on banana growth and development. Nano silver have been found efficient in controlling contaminations and increase in multiplication of shoots by three fold higher than in the control experiments (Dang Giap et al., 2018). The growth of tobacco cell culture (callus) which can be affected and highly enhanced by the introduction of multiwalled carbon nanotubes in the growth medium (Khodakovskaya et al., 2012). The effect of CNTs seems to increase in the growth of germinated embryos and root number (Rania A. Taha, Mona M. Hassan, et al., 2016).

Since there are report on use of carbon nano tubes in tissue culture for better regeneration and development in other crops, therefore, multiwalled carbon nano tube can be used to develop efficient regeneration protocol for 'Malbhog' banana. However, there is no report available on use of multiwalled carbon nano tubes in regeneration of 'Malbhog' cultivar of banana. In the present study, we report here for the first time the effect of multi walled carbon nano tubes in successful regeneration of 'Malbhog' banana.

\section{Materials and Methods}

\section{Plant materials}

Musa paradisiacal 'Malbhog' (AAB) suckers was collected from farmyard of Sivasagar district, and Chroma hydroponic nursery,
Dibrugarh, Assam.

\section{Sterilization}

The suckers were excised to a size about $6 \mathrm{~cm}$ and kept in Tween-20 solution for 30 minutes followed by washing under running tap water for 20 minutes. The suckers are again excised to a size about $3 \mathrm{~cm}$ by removing two layers and then dipped in a solution of $1 \%$ bavistin (Hi-Media®), 1\% chloramphenicol (HiMediaß) and 2\% sodium hypochlorite (HiMedia®) for 45 minutes as reported by Goswami and Handique (2013). The treated explants were then rinsed 3 times in sterile distilled water. The explants were then dipped in $50 \mathrm{mg} / \mathrm{L}-100 \mathrm{mg} / \mathrm{L}$ ascorbic acid solution for 1 hour, followed by 3-4 rinses in distilled water. The final step of sterilizing the explants was done by removing one scale and treating them with $0.1 \%$ mercuric chloride solution, followed by 3 rinses in sterile distilled water.

\section{Plant regeneration}

Suckers of about $2-3 \mathrm{~cm}$ were inoculated in the culture bottle. The solid culture medium contained MS macro and micro nutrients (Murashige and Skoog, 1962), 30g/L sucrose (Hi-Media®) and 8g/L agar (Hi-Media ${ }^{\circledR}$ ). The different concentrations of plant growth regulators were tested: BAP (2.5-7.5 mg/L), TDZ (0.05-0.22 mg/L), and in combination of BAP with NAA $(0.5-2 \mathrm{mg} / \mathrm{L})$; TDZ with NAA (0.5-2 mg/L) respectively. The explants were also inoculated in medium supplemented with different concentrations of FCNT (Functionalised carbon nano tubes), D1 and $\mathrm{D} 2$ at $10,50,100 \mu \mathrm{g} / \mathrm{mL}$ respectively. The $\mathrm{pH}$ of the medium was adjusted to 5.8 before autoclaving. Cultures were kept at $25 \pm 2{ }^{\circ} \mathrm{C}$ with 16 hours illuminations at 2000 lux and 8 hours dark phases and the observation was recorded after 7days of incubation. The regenerated explants were subcultured for 3-4 
times on the same media at an interval of six weeks to get multiple shoots. The well grown elongated shoots were transferred to half strength MS medium containing 0.5 and $1.0 \mathrm{mg} / \mathrm{L}$ NAA for the induction of roots and also to MS medium without hormones. The well rooted plants were then removed from media and washed off for agar traces. The plantlets were transferred to polybags in greenhouse and then to fields.

\section{Results and Discussion}

\section{Establishment of aseptic culture}

Establishment of aseptic culture was difficult, because the explants were taken from sucker in field conditions. Further, the browning of explants is reduced by treating the explants with ascorbic acid $(100 \mathrm{mg} / \mathrm{L})$ at different exposure time (30-60 min). Treatment with ascorbic acid for 60 minutes was found effective in culture establishment.

\section{Induction of shoots}

The explants were cultured on MS media supplemented with growth hormone alone or in combinations. The different concentrations of BAP $(2.5,5.0,7.5 \mathrm{mg} / \mathrm{L})$, TDZ $(0.05,0.11$, $0.22 \mathrm{mg} / \mathrm{L})$ and NAA $(0.5,1.0,1.5 \mathrm{mg} / \mathrm{L})$ were used alone and in combinations. BAP at $2.5 \mathrm{mg} / \mathrm{L}$ showed better result as 7.25 shoots per explants was produced over all the other treatments (Table 1). The lowest rate of initiation of shoot was observed when BAP concentration was increased to $7.5 \mathrm{mg} / \mathrm{L}$.

When TDZ was used alone for shoot initiation it was observed that TDZ at $0.11 \mathrm{mg} / \mathrm{L}$ produced maximum number of shoots $(7.5$ shoots per explant) as shown in (Table 1), over all the other treatments of TDZ. The effect of BAP and TDZ with combination of NAA was studied for shoot multiplication and it was observed that BAP at $2.5 \mathrm{mg} / \mathrm{L}+1 \mathrm{mg} / \mathrm{l}$
NAA (7.4 shoots per explants) resulted a maximum number of shoots. Similarly, TDZ at $0.11 \mathrm{mg} / \mathrm{L}+1 \mathrm{mg} / \mathrm{L}$ NAA $(6.3$ shoots per explants) showed better result.

\section{Shoot induction on MS with Multi Walled Carbon Nano tubes (MWCNT's)}

A separate study was carried out to observe the effect of multi walled carbon nano tubes along with BAP on shoot initiation and multiplication. Functionalised carbon nano tube (FCNT), D1 and D2 were used in culture media after dispersing the nano tubes in Ultrasonicator (Fig. 1D). FCNT, D1 and D2 were studied at 10,50 and $100 \mu \mathrm{g} / \mathrm{mL}$ for shoot induction. MS media having $2.5 \mathrm{mg} / \mathrm{L}$ BAP with $100 \mu \mathrm{g} / \mathrm{mL}$ FCNT (Fig. 1G) produced maximum of 12.5 shoots per explants as shown in (table 2), compared to treatments without the effect of FCNTs. Similarly, when D1 is used in media at $2.5 \mathrm{mg} / \mathrm{L} \mathrm{BAP}+50 \mu \mathrm{g} / \mathrm{mL}$ D1 showed better result over all the other treatments of D1. $\mathrm{BAP}$ at $2.5 \mathrm{mg} / \mathrm{L}+100 \mu \mathrm{g} / \mathrm{mL} \mathrm{D} 2$ produced maximum number of shoots. Therefore the use of FCNTs in the growth medium showed positive response for efficient regeneration with highest number of shoots compared to all the other treatments (Table 2).

\section{Rooting of the proliferated shoots}

Different concentrations of NAA $(0.5 \mathrm{mg} / \mathrm{L}$ and $1.0 \mathrm{mg} / \mathrm{L}$ ) were supplemented on both, full and half strength MS basal medium. The NAA concentration at $1.0 \mathrm{mg} / \mathrm{L}$ showed positive response in root initiation over all the other (Fig. 1I). Full strength MS medium containing NAA showed very poor response in root initiation. The roots were also developed when MS medium was not fortified with hormones.

The results of the study reported here showed that the use of ascorbic acid for 60 minutes 
was efficient in establishment of culture otherwise; it would lead to death of explants due to browning. Similar results were reported by Goswami and Handique (2013), when they treated the explants with ascorbic acid, citric acid and a solution of ascorbic acid and citric acid $100 \mathrm{mg} / \mathrm{L}$ for 1 hour before surface sterilization and $50 \mathrm{mg} / \mathrm{L}$ Ascorbic Acid, $50 \mathrm{mg} / \mathrm{L}$ Citric Acid and a solution of Ascorbic acid and citric acid $100 \mathrm{mg} / \mathrm{L}$ for 10minutes.

Table.1 MS basal medium treatments with different concentration of growth regulators for shoot multiplication

\begin{tabular}{|c|c|c|c|c|c|c|}
\hline \multirow[t]{2}{*}{ Treatments } & \multicolumn{4}{|c|}{ Plant growth regulators (mg/L) } & \multirow{2}{*}{$\begin{array}{c}\text { No.of } \\
\text { shoots per } \\
\text { explant }\end{array}$} & \multirow{2}{*}{$\begin{array}{c}\text { Shoot } \\
\text { length } \\
(\mathrm{cm})\end{array}$} \\
\hline & BAP mg/L & $\begin{array}{l}\text { TDZ } \\
\mathrm{mg} / \mathrm{L}\end{array}$ & $\begin{array}{c}\text { BAP + } \\
\text { NAA } \\
\text { mg/L }\end{array}$ & $\begin{array}{c}\text { TDZ + } \\
\text { NAA } \\
\text { mg/L }\end{array}$ & & \\
\hline T1 & - & - & - & - & 0.6 & 0.55 \\
\hline $\mathbf{T 2}$ & 2.5 & - & - & - & 7.25 & 4.80 \\
\hline T3 & 5 & - & - & - & 3.5 & 3.60 \\
\hline T4 & 7.5 & - & - & - & 1.75 & 2.63 \\
\hline T5 & - & 0.05 & - & - & 2 & 3.10 \\
\hline T6 & - & 0.11 & - & - & 7.5 & 4.80 \\
\hline T7 & - & 0.22 & - & - & 1.5 & 3.60 \\
\hline T8 & - & - & $1+0.5$ & - & 0.8 & 2.25 \\
\hline T9 & - & - & $2.5+1$ & - & 7.4 & 4.36 \\
\hline T10 & - & - & $5+2$ & - & 4.2 & 2.23 \\
\hline T11 & - & - & - & $0.05+0.5$ & 1.5 & 3.36 \\
\hline T12 & - & - & - & $0.11+1$ & 6.3 & 3.96 \\
\hline T13 & - & - & - & $0.22+2$ & 1.2 & 2.50 \\
\hline
\end{tabular}

Table.2 MS medium supplemented with MWCNT's and optimum hormone concentration

\begin{tabular}{|r|c|c|c|c|}
\hline Treatments & $\begin{array}{c}\text { MWCNT's } \\
\text { FCNT }(\boldsymbol{\mu g} / \mathbf{m L})\end{array}$ & BAP $(\mathbf{m g} / \mathbf{m L})$ & $\begin{array}{c}\text { No. of shoots } \\
\text { per explant }\end{array}$ & $\begin{array}{c}\text { Shoot } \\
\text { length }(\mathbf{c m})\end{array}$ \\
\hline T1 & 10 & 2.5 & 7.23 & $\mathbf{4 . 6}$ \\
\hline T2 & 50 & 2.5 & 7.26 & $\mathbf{4 . 8}$ \\
\hline T3 & 100 & 2.5 & 12.5 & $\mathbf{5 . 2}$ \\
\hline & D1 $(\boldsymbol{\mu g} / \mathbf{m L})$ & & & \\
\hline T4 & 10 & 2.5 & 4.5 & $\mathbf{3 . 2 6}$ \\
\hline T6 & 50 & 2.5 & 7.0 & $\mathbf{4 . 5}$ \\
\hline & 100 & 2.5 & 4.5 & $\mathbf{3 . 1}$ \\
\hline T7 & $\mathbf{D 2}(\boldsymbol{\mu g} / \mathbf{m l})$ & & & \\
\hline T8 & 10 & 2.5 & 4.0 & $\mathbf{2 . 8 6}$ \\
\hline & 50 & 2.5 & 3.2 & $\mathbf{2 . 7}$ \\
\hline
\end{tabular}


Fig.1 Regeneration of Musa paradisiaca 'Malbhog banana' through different concentration of plant growth regulators and multi walled carbon nano tubes. (A) Inoculation of meristematic shoot tips. (B) Establishment of culture (green and swelling). (C)Initiation of shoot on MS supplemented with BAP. (D) Multi walled carbon nano tubes dispersed in Ultrasonicator. (E) SEM image of FCNT. (F) Graph showing elements of FCNT. (G) Shoot induction on MS supplemented with FCNTs (Functionalised carbon nano tubes). (H) Shoot clusters. (I) Rooted plantlet after 4 months

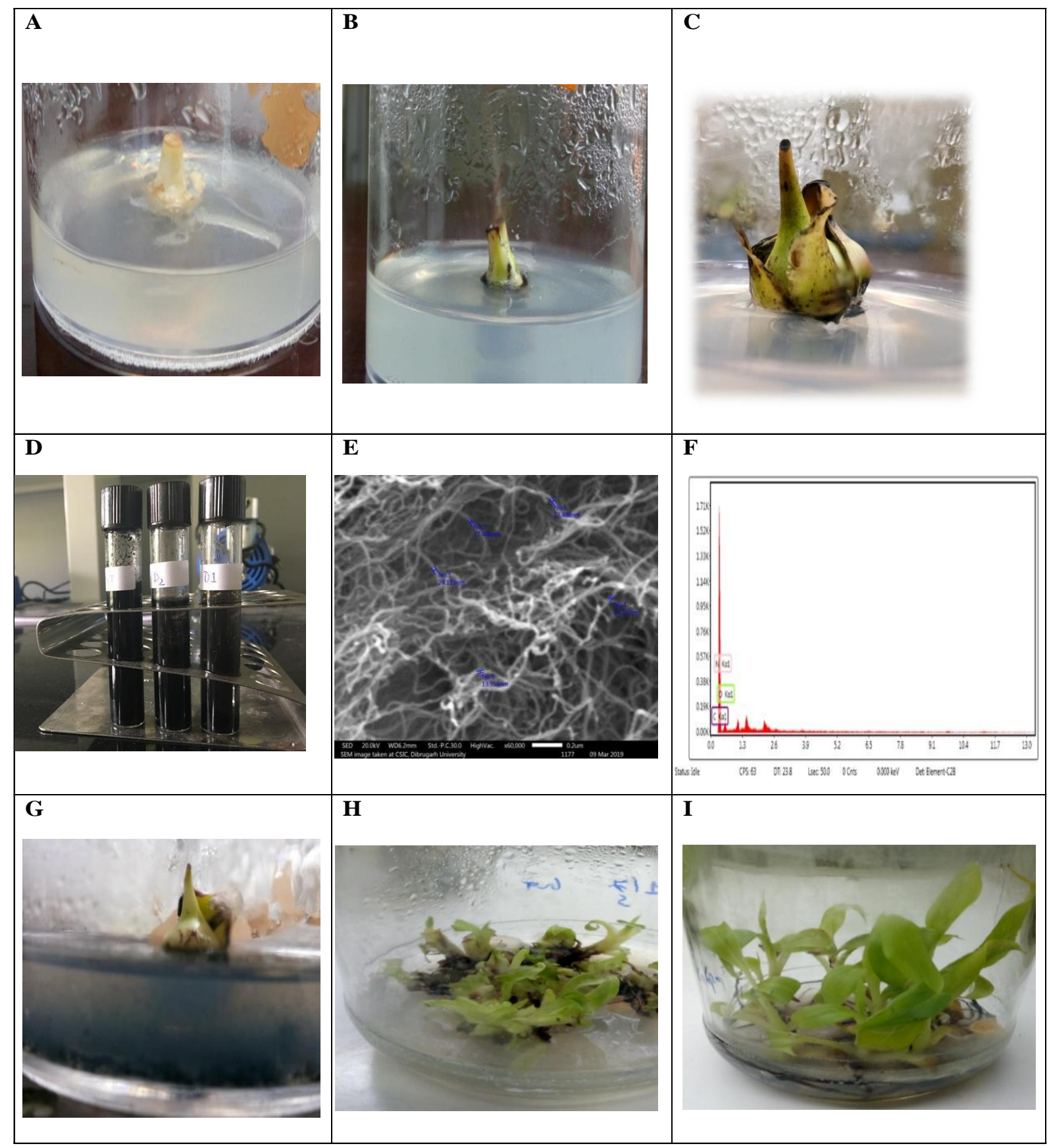


The present research work studied the effect of BAP, TDZ and NAA in regeneration of successful plant and found that different concentrations and combinations have diverse effects in their growth and development. Several other groups have also used BAP as plant growth regulators for example, Cronauer and Krikorian (1984) carried out micropropagation of banana with the cultivar 'Philippine Lactum' (AAA), 'Grand Naine' (AAA), 'Saba' (ABB), 'Pelipita' (ABB) and found that $5 \mathrm{mg} / \mathrm{L} \mathrm{BA}$ was the best for shoot multiplication. Similarly Mendes et al., (1999) observed multiplication of shoot tips of cv. 'Naincao' on MS media supplemented with $4.5 \mathrm{mg} / \mathrm{L}$ BA. However, Arinaitwe et al., (2000) have also compared various traditional cytokinins $(16.8-28.8 \mu \mathrm{M})$ and lower concentrations $(0.045-9.1 \mu \mathrm{M})$ of TDZ for in vitro multiplication of three cultivars ('Kibuzi' (AAA), 'Ndiziwemiti' (ABB) and 'Bwara' (AAA) and found that TDZ as better for multiplication than other cytokinins. Shoot multiplication of 'Ndiziwemiti' progressively increased as the concentration of TDZ increased (9.5 shoots/ explants) whereas the proliferation rate of 'Bwara' and 'Kibuzi' decreased (2-5.4 shoots/ explants) with increasing concentration of TDZ. The use of single plant growth regulator was found to have better response in terms of shoot regeneration than the combinations of growth regulators.

The use of multi walled carbon nanotubes like FCNTs (Functionalised carbon nano tubes) was found to have positive effects in multiplication and successful regeneration. As it was reported in Khodakovskaya et al., (2012) that multi-walled carbon nanotubes enhanced the growth of tobacco cell culture (55-64 \% increase over control) in an extensive range of concentrations. In the present study the use of FCNTs in the growth medium was found to be most effective in multiplication and development compared to all the other treatments evaluated. According to Khodakovskaya et al., (2012), FCNTs (Functionalised carbon nano tubes) improves the root elongation as compared to MS supplemented with growth regulators. Canas et al., (2008) determined the effect of CNTs (carbon nano tubes) on root elongation of six different crop species; tomato, carrot, lettuce, cucumber, onion and cabbage. The improvements in the shoots and roots development may be due to the uptake and accumulation of multi-walled CNTs by roots followed by the movement from roots to leaves (Smirnova et al., 2012). The response showed with the effect of MWCNTs was found to positive response in developing a rapid micropropagation protocol for 'Malbhog' banana.

In conclusion the regeneration of Musa paradisiaca 'Malbhog' banana has an increasing demand in North Eastern India, due to its high nutritional value, taste and aroma. Our results show that use of multi walled carbon nano tubes in regeneration is efficient because the MWCNT's used in this study were in range of 12-25 nm (Fig. 1E) which can be inferred that it would be compatible with the general pore size of the

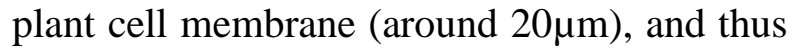
be enable them to affect changes by entry into the cells. The results reported here provide novel information on various factors that influence the culture establishment and shoot initiation of malbhog banana. Further future research would be required to study the effects of MWCNT's in shoot initiation at molecular level.

\section{Acknowledgement}

We thank Dibrugarh University for providing necessary infrastructure and facilities needed for the completion of the work. This study was generously supported by Professor Gaurav Verma of DR. SSB, UICET, Panjab 
University and Chroma Hydroponics Nursery, Dibrugarh, Assam for their contribution. We wish to extend our heartfelt gratitude to Dr Diganta Sarma, Head of the department of Chemistry for his help during the course of this research work and CSIC, Dibrugarh University for carrying out SEM analysis of MWCNT's. We would also like to thank Assam Agriculture University, Jorhat for their information on banana tissue and extending help in preparing this manuscript.

\section{Abbreviations}

BAP: Benzylaminopurine. MWCNT's: Multi walled carbon nano tubes. FCNT's: Functionalized carbon nano tubes. NAA: 1Napthalenacetic acid. TDZ: Thidiazuron.

\section{References}

Singh, S. K., and Jha, P. K. (2011). Differential reaction of banana varieties to Panama wilt in agroecological conditions in Bihar. Bihar Journal of Horticulture, 1, 18-20.

KUMARI, A., and KUMAR, H. (2016). Development of an Efficient Micropropagation System in Banana cv. Malbhog (AAB). Advances in Life Sciences, 5, 3487-3494.

Tomekpe, K., Kwa, M., Dzomeku, B. M., \&Ganry, J. (2011). CARBAP and innovation on the plantain banana in Western and Central Africa. International Journal of Agricultural Sustainability, 9(1), 264-273.

Barker, W. G. (1959). A system of maximum multiplication of the banana plant. Tropical Agriculture, 3, 275-284.

De Smet, K., du Montcel, H. T., \&Swennen, R. (1995). Variability in storage potential of banana shoot cultures under medium term storage conditions. Plant Cell, Tissue and Organ Culture, 42(3), 269-274.
Do, D. G., Dang, T. K. T., Nguyen, T. H. T., Nguyen, T. D., Tran, T. T., \&Hieu, D. D. (2018). Effects of nano silver on the growth of banana (Musa spp.) cultured in vitro. Journal of Vietnamese Environment, 10(2), 92-98.

Helaly, M. N., El-Metwally, M. A., ElHoseiny, H., Omar, S. A., and ElSheery, N. I. (2014). Effect of nanoparticles on biological contamination of'invitro'cultures and organogenic regeneration of banana. Australian Journal of Crop Science, 8(4), 612.

N K Goswami and Dr. P. J. Handique, (2013), In Vitro Sterilization protocol for Micropropagation of Musa (AAA group) 'Amritsagar' Musa (AAB group) 'Malbhog' and Musa (AAB group) 'Chenichampa' Banana. Indian Journal of Applied Research, 3 (6),5154.

CRONAUER, S. S., and Krikorian, A. D. (1984). Multiplication of Musa from excised stem tips. Annals of Botany, 53(3), 321-328.

Mc Gehee, D.L., Lahiani, M. H., Irin, F., Green, M.J., and Khodakovskaya, M. V. (2017). Multiwalled carbon nanotubes dramatically affect the fruit metabolome of exposed tomato plants. ACS applied materials and interfaces, 9(38), 32430-32435.

Mendes, B.M.J., Filippi, S.B., Demétrio, C.G.B., and Rodriguez, A.P.M (1999). A statistical approach to study the dynamics of micropropagation rates, using banana (Musa spp.) as an example. Plant Cell Reports, 18(12), 967-971.

Arinaitwe, G., Rubaihayo, P. R., and Magambo, M. J. S. (2000). Proliferation rate effects of cytokinins on banana (Musa spp.) cultivars. Scientia Horticulturae, 86(1), 13-21.

Khodakovskaya, M. V., De Silva, K., Biris, 
A. S., Dervishi, E., \&Villagarcia, H. (2012). Carbon nanotubes induce growth enhancement of tobacco cells. ACS nano, 6(3), 2128-2135.

Cañas, J. E., Long, M., Nations, S., Vadan, R., Dai, L., Luo, M., .. \&Olszyk, D. (2008). Effects of functionalized and nonfunctionalized single- walled carbon nanotubes on root elongation of select crop species. Environmental Toxicology and Chemistry: An International Journal, 27(9),19221931.

Smirnova, E., Gusev, A., Zaytseva, O., Sheina, O., Tkachev, A., Kuznetsova, E., and Kirpichnikov, M. (2012).
Uptake and accumulation of multiwalled carbon nanotubes change the morphometric and biochemical characteristics of Onobrychis arenaria seedlings. Frontiers of Chemical Science and Engineering, 6(2), 132138.

Thangavelu, R., Kumar, K. M., Devi, P. G., and Mustaffa, M. M. (2012). Genetic diversity of Fusarium oxysporum f. sp. cubense isolates (Foc) of India by inter simple sequence repeats (ISSR) analysis. Molecular biotechnology, 51(3), 203-211.

\section{How to cite this article:}

Indrani Chetia, Amrita Kashyap Chaliha, Manab Bikash Gogoi and Gaurav Verma. 2020. Establishment of Efficient In-vitro Regeneration Protocol in 'Malbhog' Banana (Musa paradisiaca) using MWCNTs and Plant Growth Regulators. Int.J.Curr.Microbiol.App.Sci. 9(08): 2930-2937. doi: https://doi.org/10.20546/ijcmas.2020.908.328 